\title{
Estudo sobre a atuação do MERCOSUL Cultural nas ações de preservação do patrimônio documental bibliográfico
}

\author{
Marcia Carvalho Rodrigues \\ Doutora; Universidade Federal do Rio Grande, Rio Grande, RS, Brasil; \\ marciarodriguesfurg@gmail.com
}

\begin{abstract}
Resumo: Este artigo tece um breve histórico do MERCOSUL e do MERCOSUL Cultural, órgão responsável pela promoção e divulgação dos valores e tradições culturais dos países integrantes do bloco. O estudo propôs-se a investigar as ações do MERCOSUL Cultural com vistas à preservação do patrimônio documental bibliográfico. Seguindo uma abordagem qualitativa, fez uso das revisões bibliográfica e documental para a construção teórica. Os resultados da pesquisa demonstram que a cultura, de uma maneira geral, não tem ocupado posição de destaque nas ações e iniciativas do MERCOSUL. A presença dessa lacuna evidencia a necessidade de estímulo a estudos e pesquisas referentes à busca pela integração entre os países, dando a devida consideração às questões de ordem cultural, trazendo à tona a importância dos estudos voltados à preservação e à valorização do patrimônio cultural das nações.
\end{abstract}

Palavras-chave: Patrimônio documental bibliográfico. Patrimônio cultural. MERCOSUL.

\section{Introdução}

O presente artigo é resultante de uma das etapas da pesquisa de doutoramento desenvolvida pela autora, cujo objetivo geral consistiu na interpretação das políticas de preservação do patrimônio documental bibliográfico no âmbito dos países do MERCOSUL executadas pelas bibliotecas nacionais, tendo como foco principal as leis que regulam o depósito legal de publicações.

Parte-se do pressuposto de que as bibliotecas representam uma importante parcela da memória da cultura coletiva de um país, sendo seu dever salvaguardar e tornar público este patrimônio, buscando alternativas de preservação das coleções, sem excluir o acesso às mesmas. Igualmente, a 
necessidade de acompanhamento das inovações tecnológicas no campo do tratamento da informação e investimentos em projetos que envolvam a cooperação internacional há muito tempo passou a ser vista como fator de competitividade e uma área estratégica a ser desenvolvida. A partir do exposto, propôs-se uma investigação sobre a atuação do MERCOSUL nas ações de preservação do patrimônio documental bibliográfico, tendo em vista, ainda, tanto a relevância do bloco dentro do contexto sócio-político-econômico mundial e regional, quanto à importância da cultura para as relações internacionais.

A hipótese levantada neste estudo se baseia na suposição de que, apesar de algumas iniciativas terem sido tomadas no sentido de buscar alternativas conjuntas para preservar e valorizar o patrimônio cultural dos países que integram o MERCOSUL, a cultura, de uma maneira geral, não tem ocupado posição de destaque nas ações e iniciativas do bloco.

O estudo se apresenta sob um enfoque qualitativo e fez uso das revisões bibliográfica e documental para a construção teórica.

\section{O MERCOSUL}

Desde que Brasil e Argentina se tornaram países independentes, sempre houve momentos de aproximação entre os governos como, também, outros de rivalidade e desconfiança. Mas, ao observar o histórico de suas relações, percebe-se o interesse, antigo, em cooperar mutuamente de forma a possibilitar a sua integração econômica. Para Bandeira (1995 ${ }^{1}$ apud CARVALHO, 20012002, p. 79),

As relações Brasil e Argentina sempre se mantiveram em compasso cauteloso, ambos temiam que o outro assumisse uma posição hegemônica na América do Sul. A interdependência [...] era tão forte que acabava por inibir os conflitos, quaisquer que fossem as causas, compelindo-os em meio a tensões e desconfianças, a empreenderem, periodicamente, esforços comuns para o entendimento e a cooperação.

Amicci (2012, p. 110, tradução nossa) corrobora, afirmando: 
Assim, ainda que seus vínculos bilaterais tenham sido marcados por momentos de inquietante competição geopolítica, também resultaram em interessantes momentos de cooperação - RocaCampos Salles, de la Plaza-Brás, Peron-Vargas, FrondiziKubistchek-Quadros, que foram forjando os elos da cadeia de base que conduziram, gradualmente, à integração atual.

Notadamente, ambos países fazem parte da Associação Latino-Americana de Integração (ALADI) ${ }^{2}$, o maior bloco econômico da América Latina, desde os seus primórdios, ainda na década de 1960. Em 1985, porém, foi dado o primeiro passo concreto para a efetiva construção de uma relação mais estreita entre Brasil e Argentina, com a assinatura da Declaração de Iguaçu pelos então presidentes José Sarney e Raúl Alfonsín. Leme (2006) observa que a aproximação entre os dois países passou a ocorrer, de forma mais consistente, a partir de 1979, quando a necessidade de "[...] resolver o contencioso referente ao aproveitamento hidrelétrico do Rio Paraná e estreitar laços de cooperação nos campos da segurança e da energia nuclear." (LEME, 2006, p. 12) se tornou premente. A partir daí, as relações entre os dois países avançaram no sentido de ampliação da confiança mútua, propiciando o diálogo entre as nações:

Para os presidentes Alfonsín e Sarney, o modelo europeu de integração regional foi uma referência importante e ambos consideravam que a integração não apenas seria econômica, mas, também, política e cultural (LEME, 2006, p. 14).

Outro fator igualmente importante neste processo foi a redemocratização dos sistemas políticos brasileiro e argentino, o qual possibilitou a assinatura de uma série de acordos posteriores, tais como:

a) a Ata para Integração Brasileiro-Argentina, em 1986, que estabelece o Programa de Integração e Cooperação Econômica (PICE);

A Ata baseia-se nos princípios que mais tarde viriam a nortear o Tratado de Assunção, que criaria o MERCOSUL: flexibilidade (para permitir ajustamentos no ritmo e nos objetivos); gradualismo (para avançar em etapas anuais); simetria (para harmonizar as políticas específicas que interferem na competitividade setorial) e equilíbrio dinâmico (para propiciar uma integração setorial uniforme) (BRASIL, [2015], grifo do autor).

b) o Tratado de Integração, Cooperação e Desenvolvimento, em 1988, o qual buscava estabelecer uma área de livre comércio entre os países 


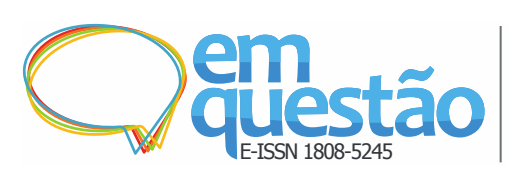

dentro de um prazo de 10 anos. Segundo o Acordo de complementação econômica ${ }^{\circ} 14$;

$\mathrm{Na}$ oportunidade, foram assinados 24 Protocolos sobre diversos temas, tais como: bens de capital, trigo, produtos alimentícios industrializados, indústria automotriz, cooperação nuclear, transporte marítimo, transporte terrestre (BRASIL, [2015]).

c) o Tratado para o Estabelecimento de um Estatuto das Empresas Binacionais Brasileiro-Argentinas, em 1990;

d) o Acordo de Complementação Econômica no. 14, em 1990, “[...] que incorporou os 24 Protocolos anteriormente acordados e que se constituiu o referencial adotado, posteriormente, no Tratado de Assunção (1991)" (BRASIL, [2015]).

Em 1991, Brasil, Argentina, Uruguai e Paraguai assinaram o Tratado de Assunção, criando o MERCOSUL. Entre 1991 e 1994, o MERCOSUL passou por um período de transição, caracterizado pelo desenvolvimento de políticas econômicas, comerciais e tarifárias de uso comum entre os países membros, período este previsto no Tratado. Na sequência, três protocolos foram assinados, formalizando a integração e institucionalizando instituições governamentais: o Protocolo de Brasília para a Solução de Controvérsias (1991); o Protocolo de Ouro Preto - Protocolo Adicional ao Tratado de Assunção sobre a Estrutura Institucional do MERCOSUL (1994); e o Protocolo de Olivos para a Solução de Controvérsias no MERCOSUL (2003).

O MERCOSUL é uma união aduaneira formada, atualmente, por seis países da América do Sul: Brasil, Argentina, Paraguai, Uruguai, Venezuela e Bolívia. Desde a sua criação, outros países sul-americanos têm demonstrado interesse em fazer parte da união econômica, como é o caso da Venezuela e da Bolívia, os quais só alcançaram o status de membros plenos em 2012 e 2015, respectivamente. O MERCOSUL tem, ainda, como Estados associados, os seguintes países: Chile, Peru, Colômbia, Equador, Guiana e Suriname (MERCOSUL, 2016a). 
Figura 1 - Países membros do MERCOSUL: área e população

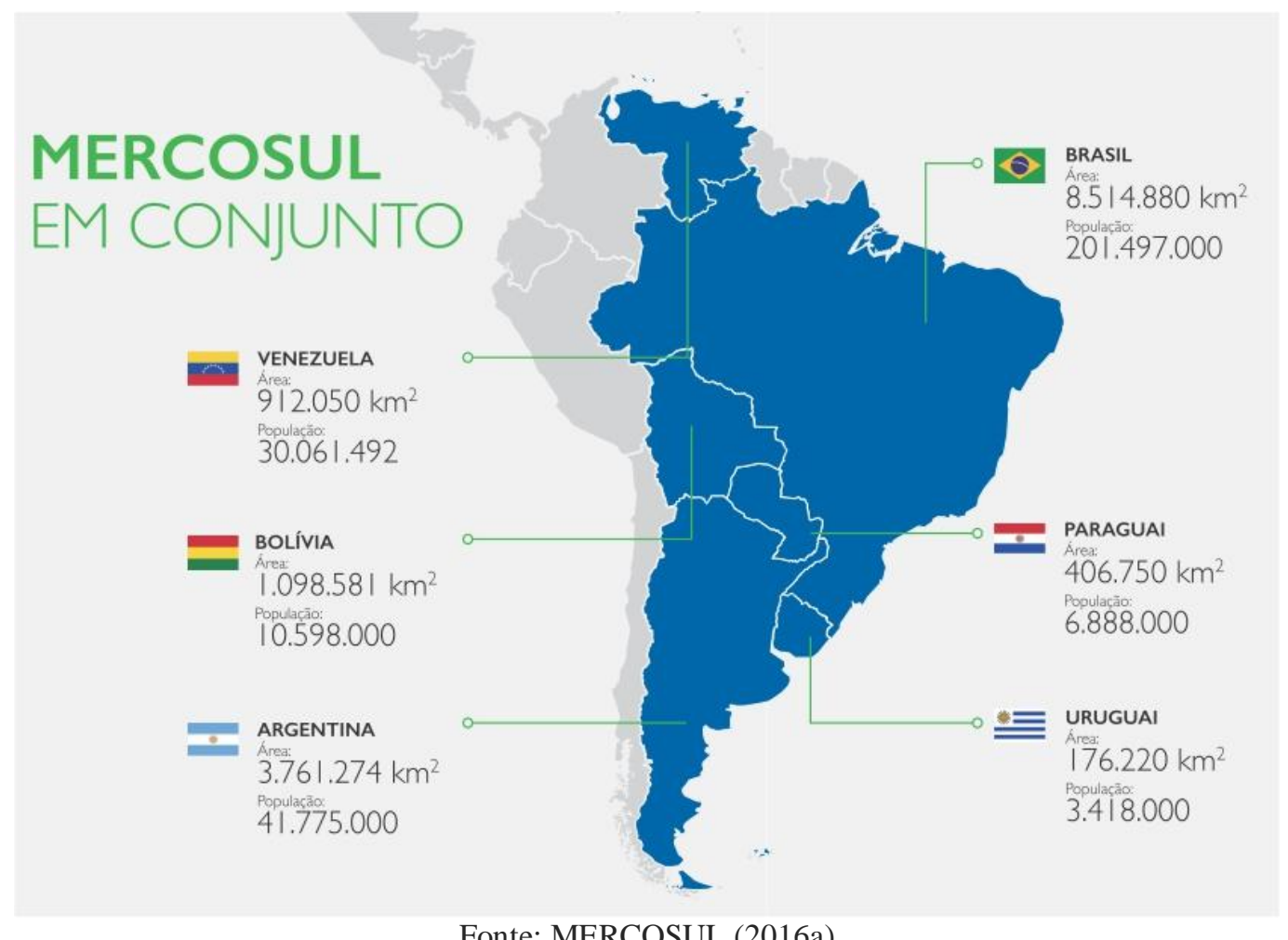

Fonte: MERCOSUL (2016a).

A Figura 1 mostra a extensão territorial do MERCOSUL: quase 15 milhões de $\mathrm{km}^{2}$, o que equivale a cerca de $75 \%$ da área total da América do Sul. A população dos países membros, somada, chega a cerca de 295 milhões de habitantes, o que corresponde a, aproximadamente, $73 \%$ da totalidade da população sul-americana, ajudando a compor um quadro amplo, rico e diversificado em termos culturais, religiosos, linguísticos, étnicos e ambientais. O MERCOSUL como um conjunto apresenta, ainda, as seguintes características:

a) é uma das maiores potências energéticas do mundo, sendo detentor da maior reserva de petróleo do planeta;

b) é um importante produtor agrícola, destacando-se sua capacidade de produção das cinco principais culturas alimentares globais: trigo, milho, soja, açúcar e arroz;

c) o MERCOSUL, se fosse considerado um único país, ocuparia a quinta posição na economia mundial, apresentando um Produto Interno Bruto (PIB) nominal de US\$ 3,2 trilhões (MERCOSUL, 2015; MERCOSUL, 2016a). 
Em relação à história do MERCOSUL, é relevante destacar que o contexto em que se deu a sua criação foi marcado pelo surgimento de outros acordos de cooperação, como a Cooperação Econômica da Ásia e do Pacífico (Asia-Pacific Economic Cooperation - APEC), em 1989; o Tratado Norte-Americano de Livre Comércio (North American Free Trade Agreement - NAFTA), em 1992; e a União Europeia (European Union - EU), em 1993. O momento político em que se deu a sua formação, marcado pela crescente onda de globalização da economia capitalista, reflete alguns elementos comuns que motivaram as suas formações, como os objetivos desenvolvimentistas presentes em todas as iniciativas, os quais buscavam:

i) uma maior eficiência na produção, pela especialização crescente dos agentes econômicos;

ii) altos níveis de produção pelo maior aproveitamento das economias de escala permitidas pela ampliação de mercado;

iii) melhor posição de barganha no plano internacional, em virtude das dimensões ampliadas da nova área, melhorando os termos de intercâmbio;

iv) mudanças positivas na eficiência econômica dos agentes;

v) transformação na qualidade e quantidade dos fatores de produção, avanço tecnológico;

vi) mobilidade de fatores através das fronteiras entre os países membros, permitindo alocação otimizada de recursos;

vii) coordenação de políticas monetárias e fiscais num sentido teoricamente mais racional, já subordinadas a uma lógica impessoal não à pressão de grupos setoriais ou correntes politicamente influentes em escala nacional;

viii) os objetivos do pleno emprego, altas taxas de crescimento econômico e de uma melhor distribuição de renda tornar-se-iam metas comuns (CARVALHO, 2001-2002, p. 86).

A criação de blocos econômicos regionais, ou seja, países próximos entre si que, mediante tratado, estabelecem acordos através dos quais concordam em abrir mão da soberania nacional em troca de privilégios de ordem econômica e financeira, se tornou a resposta para o contexto econômico vigente. Assim surge o MERCOSUL: instituído com a finalidade de estabelecer uma aliança comercial entre Brasil, Argentina, Paraguai e Uruguai, visando a dinamizar a economia regional através do intercâmbio de mercadorias, tecnologias, pessoas, força de trabalho e capitais. Sua origem deriva, diretamente, do Tratado de Assunção (1991). A partir de acordos decorrentes deste Tratado, o processo de 
integração entre os quatro países se acelerou e, em 31 de dezembro de 1994, foi oficializado o MERCOSUL.

Enquanto união aduaneira, o MERCOSUL facilita a circulação de mercadorias, reduz e/ou elimina taxas de importação entre os países membros e adota uma Tarifa Externa Comum (TEC), através da qual são taxados os produtos provenientes de países estrangeiros ao bloco (não membros). Destaque-se aqui, porém, que os blocos econômicos são classificados de acordo com o grau de proximidade e integração entre os seus países integrantes. O MERCOSUL, atualmente classificado como união aduaneira, caminha rumo à consolidação como mercado comum, entendido como

[...] um processo bastante avançado de integração econômica, garantindo-se a livre circulação de pessoas, bens, serviços e capitais, ao contrário da fase como União Aduaneira, quando o intercâmbio restringia-se à circulação de bens. No Mercado Comum circulam bens, serviços e os fatores de produção (capitais e mão-de-obra) e pressupõe-se a coordenação de políticas macroeconômicas, devendo todos os países-membros seguir os mesmos parâmetros para fixar taxas de juros e de câmbio e para definir políticas fiscais (BRASIL, [200?]).

Para que se efetive sua passagem de união aduaneira para mercado comum é necessário, portanto, que o MERCOSUL não apenas facilite a livre circulação de mercadorias, mas assegure a livre circulação de capital e mão-de-obra, o que implica, no caso da mão-de-obra, por exemplo, na supressão das barreiras pautadas na nacionalidade dos trabalhadores, permitindo uma condição de igualdade entre cidadãos de diferentes nacionalidades que circulam entre os países membros do acordo.

No Tratado de Assunção, predominavam os objetivos de natureza comercial e não havia referência à cultura, assim como não havia referência a outras áreas, como a educação e o desenvolvimento científico e tecnológico, por exemplo. Porém, enquanto proposta de integração, o MERCOSUL precisou avançar para além dos fenômenos econômicos e comerciais, buscando alternativas de cooperação em outras áreas, inclusive através da cultura.

Com o avanço dos processos de globalização econômica, as relações internacionais têm passado a visualizar a cultura, cada vez mais, como 
importante instrumento de cooperação entre os povos, colaborando para a construção de vínculos de confiança e estimulando o diálogo entre as nações. $\mathrm{O}$ binômio cultura/desenvolvimento tem ocupado, cada vez mais, posição de destaque nas agendas dos governos. A justificativa pode ser encontrada nas estatísticas, que comprovam que o setor cultural é peça fundamental no desenvolvimento sustentável de uma nação, gerando renda, empregos, tributos, educação e bem-estar social. Tendo por base a relevância da cultura no processo de integração regional, no ano seguinte à assinatura do Protocolo de Ouro Preto, que institucionalizou a estrutura administrativa do MERCOSUL, criando o Conselho de Mercado Comum (CMC) - órgão superior, político e decisório, responsável pela condução das políticas de integração - e o Grupo Mercado Comum (GMC) - órgão executivo, responsável pela execução das decisões do CMC, criou-se a Reunião de Ministros de Cultura do MERCOSUL (RMC). Esse é o tema de nossa próxima discussão.

\subsection{O MERCOSUL Cultural}

No ano seguinte à assinatura do Tratado de Assunção, em 1992, reuniram-se, em Brasília, representantes da área cultural dos quatro países membros do MERCOSUL, a fim de debater questões relacionadas à cooperação e à integração no campo da cultura. Em linhas gerais, este encontro discutiu:

1) a compatibilização das legislações nacionais, visando a facilitar a livre circulação de bens e serviços culturais na região, o breve trâmite aduaneiro, com o "objetivo de formar um mercado cultural comum do MERCOSUL, inclusive com fins comerciais"; 2) a harmonização das legislações nacionais em matéria de incentivos fiscais em favor de projetos culturais, bem como na área de direitos autorais; 3) o apoio a projetos culturais e artísticos conjuntos; 4) a implementação de medidas para salvaguardar o patrimônio histórico e cultural da região, especialmente o projeto das missões jesuíticas guaranis; e 5) a elaboração de inventários de bens culturais e de bancos de dados culturais em comum (HARVEY, 2001, p. 10, tradução nossa).

A partir deste primeiro encontro, o GMC resolveu criar a Reunião Especializada sobre Cultura (REC), a qual teria por objetivo 
[...] promover a difusão da cultura dos Estados Partes, estimulando o conhecimento mútuo dos valores e tradições culturais de cada Estado Parte, bem como empreendimentos conjuntos e atividades regionais no campo da cultura (MERCOSUL,1992).

Assim, as duas primeiras Reuniões Especializadas ocorreram no ano de 1995, uma na cidade de Buenos Aires (Argentina), em março, e a outra em Assunção (Paraguai), em agosto, respectivamente. As principais decisões tomadas a partir destas duas reuniões foram:

a) fixar um Memorando de Entendimento, através do qual os países membros acordaram sobre a importância da integração cultural para a consolidação do bloco (MERCOSUL. Reunião Especializada de Cultura, 1995a);

b) recomendar a criação da RMC como foro negociador de alto nível, em substituição à REC. Sua criação foi formalizada através da Decisão $n .^{o}$ 02/95. Os objetivos da RMC consistem em;

[...] promover a difusão e conhecimento dos valores e tradições culturais dos Estados Partes do MERCOSUL, bem como a apresentação a este Conselho [do Mercado Comum] de propostas de cooperação e coordenação no campo da cultura (MERCOSUL. Reunião Especializada de Cultura, 1995b, tradução nossa).

c) adotar um logotipo do MERCOSUL Cultural, o qual teria as seguintes funções - (1) servir de elemento visual identificador da integração cultural entre os países membros; (2) facilitar a fiscalização dos bens culturais em trânsito, e; (3) garantir um nível de excelência dos projetos, iniciativas e eventos patrocinados (MERCOSUL. Reunião Especializada de Cultura, 1995b). O logotipo foi aprovado pela Resolução $n .^{\circ}$ 122/96 (MERCOSUL. Grupo de Mercado Comum, 1996) e oficializado através da Decisão n. ${ }^{o}$ 33/08 (MERCOSUL. Conselho de Mercado Comum, 2008) (Figura 2); 
Figura 2 - Selo do MERCOSUL Cultural

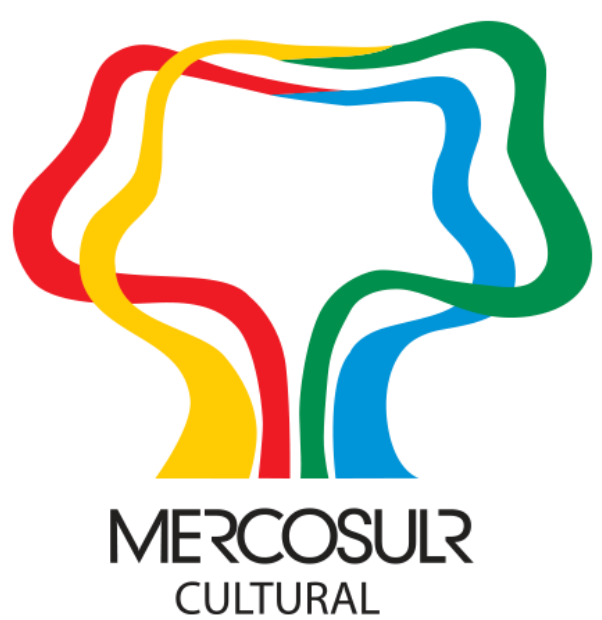

Fonte: MERCOSUL (2016b).

d) elaborar o projeto do Protocolo de Integração Cultural, o qual foi aprovado em 1996 (MERCOSUL. Conselho de Mercado Comum, 1996);

e) recomendar a criação de um fundo econômico do MERCOSUL Cultural, o qual só foi aprovado no ano de 2010. O Fundo tem por objetivo:

[...] financiar projetos e programas que fomentem a criação, circulação, promoção, proteção e difusão dos bens e serviços culturais, bem como a diversidade de expressões culturais que efetivamente contribuam com o fortalecimento do processo de integração do MERCOSUL (MERCOSUL. Conselho de Mercado Comum, 2010, tradução nossa).

Nota-se que as recomendações propostas avançaram, porém a passos bastante lentos. Soares (2011) é bastante crítica em relação à atuação do MERCOSUL Cultural como um todo, e destaca a predominância de uma visão de cultura "[...] associada ao patrimônio cultural e às indústrias culturais, que incluíam somente os setores editorial, multimídia, audiovisual, fonográfico, cinematográfico, de artesanato e desenho.” (SOARES, 2011, p. 305, tradução nossa). Para a autora,

Os temas culturais não foram para os negociadores nem uma necessidade interna do processo de integração em relação à construção de uma identidade coletiva, nem matéria de acordos comerciais e legais entre os sócios e destes com terceiros. Os interesses comerciais prevaleceram sobre as dimensões culturais, políticas e sociais de integração, relegadas a um plano secundário e seu tratamento postergado para um futuro incerto (SOARES, 2011, p. 308 , tradução nossa). 
Após reestruturação do setor cultural do MERCOSUL, com a criação da RMC, deu-se andamento às reuniões. No ano de 1996, foram em número de três. A partir de 1997, as reuniões ocorreram semestralmente, com exceção de 2014, quando ocorreu somente uma reunião. Até o final do primeiro semestre de 2016, quarenta Reuniões de Ministros da Cultura tinham sido realizadas. Soares (2011), mais uma vez, destaca que apesar da relevância política e hierárquica que a RMC possui dentro do bloco, tem proposto poucas ações desde a sua criação:

A criação da Reunião de Ministros da Cultura despertou certo otimismo entre os diversos atores culturais nacionais, que supuseram que os temas culturais passariam a fazer parte da agenda do bloco. No entanto, o resultado das atividades das Comissões Técnicas que integravam a Reunião de Ministros da Cultura patrimônio (conhecimento, proteção, conservação e valorização do patrimônio cultural, em especial, do Projeto Missões); indústrias culturais (iniciativas conjuntas nos meios de comunicação de massa); redes de informação (criação de condições para o estabelecimento de um sistema de informação cultural regional) e capacitação (formação de profissionais) - foram pouco significativas e restritas ao campo da legislação (SOARES, 2011, p. 306, tradução nossa).

Em 1996, foi criado o Parlamento Cultural do MERCOSUL (PARCUM), do qual fazem parte todos os legisladores das Comissões de Cultura ou equivalentes dos Estados Parte e Associados. O PARCUM foi criado com o objetivo principal de compatibilizar as legislações culturais dos países do bloco, priorizando a geração de marcos normativos regionais orientados à livre circulação de bens e serviços culturais entre os países membros, o que vai ao encontro dos objetivos gerais do MERCOSUL Cultural (MARTIN, 2011; SOARES, 2011). Martin (2011) destaca, porém, a dificuldade encontrada para a realização desta tarefa:

Com a finalidade de agilizar os trâmites alfandegários para exibições de artes plásticas, edições cofinanciadas e outros produtos culturais, as adequações de normas transnacionais para a legislação e dispositivos de cada nação se transformaram num sério obstáculo para o cumprimento destes objetivos (MARTIN, 2011, p. 28).

A despeito de todas as críticas ao MERCOSUL Cultural, alguns avanços se mostram presentes, especialmente a partir de 2010: 
a) em 2010, houve a criação e a instalação da Secretaria do MERCOSUL Cultural (SMC) na cidade de Buenos Aires, Argentina. Trata-se de uma estrutura permanente de apoio ao MERCOSUL Cultural, “[...] encarregada de garantir a execução, continuidade e seguimento das atividades, programas e projetos empreendidos no marco do bloco regional.” (MERCOSUL, 2016b, tradução nossa);

b) no mesmo ano, deu-se a assinatura do primeiro acordo bilateral na área da cultura, entre Brasil e Paraguai;

[...] um protocolo que prevê a valorização da diversidade, ampliação do acesso à cultura e geração de emprego e renda nas regiões de influência da Usina Hidrelétrica Itaipu Binacional, que abrange todo o Paraguai e uma ampla área do território brasileiro, com cerca de 30 municípios (INSTITUTO DO PATRIMÔNIO HISTÓRICO E ARTÍSTICO NACIONAL, 2014).

c) não se pode esquecer, ainda, a implementação do Fundo MERCOSUL Cultural, também no ano de 2010;

d) em 2012, aprovou-se o Regulamento para o Reconhecimento do Patrimônio Cultural do MERCOSUL, instrumento através do qual se estabelecem os critérios pra reconhecimento dos bens culturais e interesse regional (MERCOSUL. Conselho de Mercado Comum, 2012). Os bens culturais reconhecidos passam, então, a fazer parte de uma Lista do Patrimônio Cultural do MERCOSUL (LPCM);

Poderá ser reconhecido como Patrimônio Cultural do MERCOSUL (PCM) qualquer bem cultural, de natureza material e/ou imaterial, que:

a) manifeste valores associados a processos históricos vinculados aos movimentos de autodeterminação ou expressão comum da região perante o mundo;

b) expresse os esforços de união entre os países da região;

c) esteja diretamente relacionado a referências culturais compartilhadas por mais de um país da região;

d) constitua fator de promoção da integração dos países, com vistas a um destino comum (MERCOSUL. Conselho de Mercado Comum, 2012).

e) até 2016, foram declarados Patrimônio Cultural do MERCOSUL os seguintes bens:

- a Ponte Internacional Barão de Mauá, localizada na fronteira entre as cidades de Jaguarão (RS, Brasil) e Rio Branco (Uruguai); 
- a Payada ou Pajada, tipo de poesia oral improvisada, encontrada na Argentina, no Uruguai, no sul do Brasil, no Chile e no Paraguai;

- o Itinerário Cultural das Missões Jesuíticas Guarani, Moxos e Chiquitos, do qual são integrantes a Argentina, a Bolívia, o Brasil, o Paraguai e o Uruguai;

- o Edifício Sede da Secretaria Administrativa do MERCOSUL, localizado em Montevidéu, Uruguai.

f) em 2014, criou-se o Prêmio MERCOSUL de Artes Visuais;

g) em 2015, criou-se o Festival Cultural do MERCOSUL;

h) em 2014, foi aprovado o documento que organiza a estrutura orgânica e o regulamento interno do MERCOSUL Cultural, o qual especifica os seguintes órgãos como seus integrantes:

A estrutura orgânica do MERCOSUL Cultural está composta pela Reunião de Ministros de Cultura (RMC) e os seguintes órgãos dependentes:
a) Comitê Coordenador Regional (CCR)
b) Secretaria do MERCOSUL Cultural (SMC)
c) Comissão de Patrimônio Cultural (CPC)
d) Comissão da Diversidade Cultural (CDC)
e) Comissão de Economia Criativa e Indústrias Culturais (CECIC)
f) Comissão de Artes (CA)
g) Foro do Sistema de Informação Cultural do MERCOSUL (SICSUR) (MERCOSUL. Conselho de Mercado Comum, 2014).

A RMC é o órgão superior do MERCOSUL Cultural. Dela, fazem parte as máximas autoridades da área da cultura dos Estados Parte: Ministros e autoridades equivalentes. O CCR é órgão de assistência à RMC, do qual fazem parte funcionários indicados pelas autoridades e Ministros de Cultura de cada Estado parte. Já as Comissões tratam de temas específicos no campo da cultura e do patrimônio cultural. Posteriormente, foram incorporadas ao CCR as seguintes Comissões Técnicas: Comissão Técnica Biblioteca do MERCOSUL (CTBM), Comissão Técnica de Capacitação (CTC), Comissão Técnica de Legislação Cultural (CTLC), Comissão Técnica de Patrimônio (CTP) e Comissão Técnica Indústrias Culturais (CTIC). 


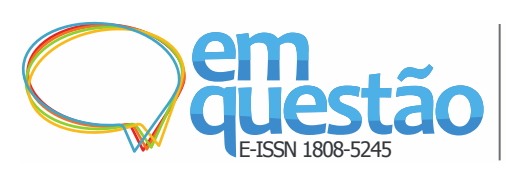

Figura 3 - Estrutura institucional do MERCOSUL Cultural

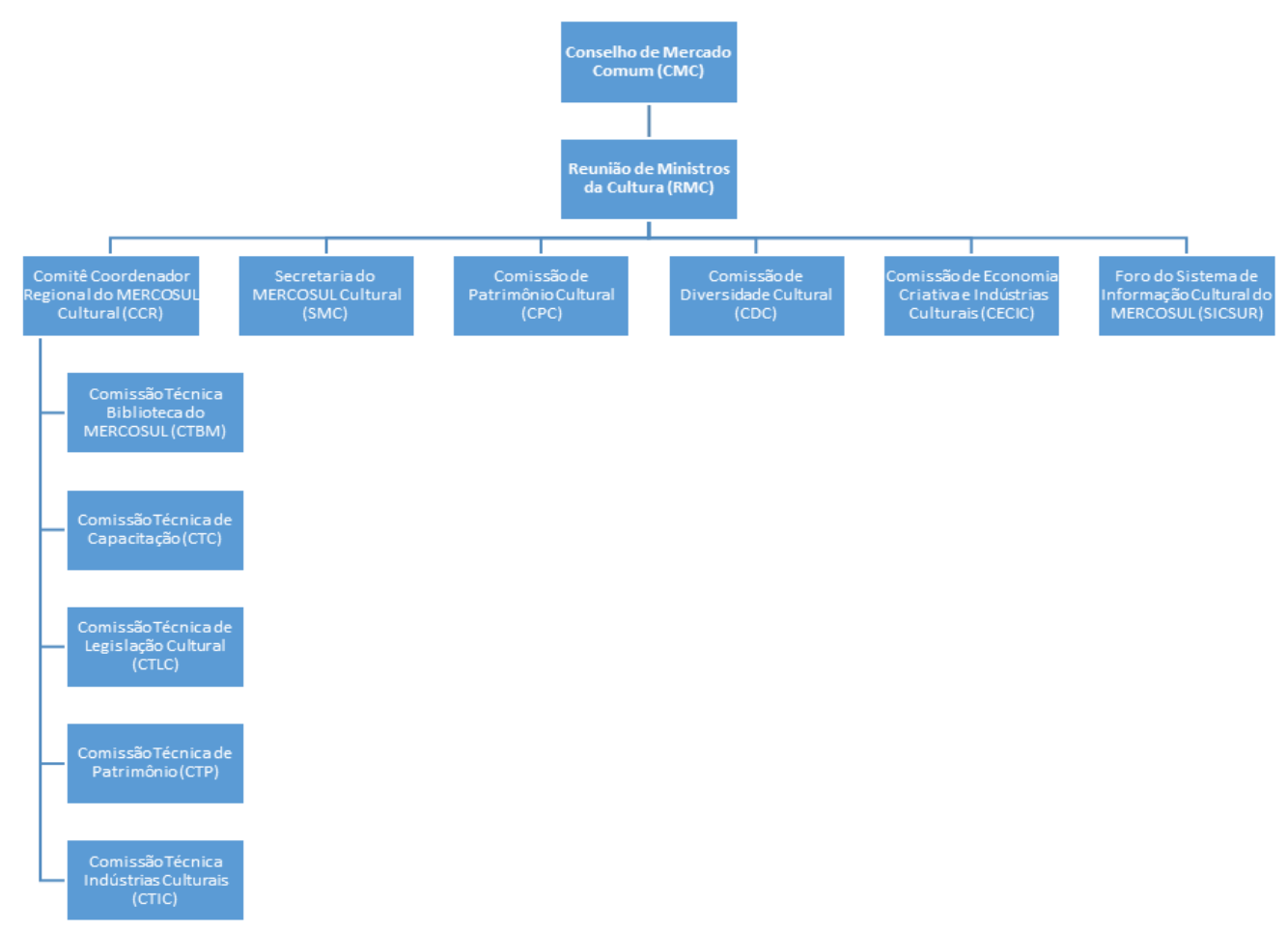

Fonte: Adaptado de MERCOSUL (2012).

Observa-se, portanto, que apesar da lentidão com que ocorrem as ações no âmbito da cultura no MERCOSUL, debates vem sendo realizados e mecanismos importantes vem sendo criados, ou seja, a cultura está, aos poucos, se fazendo presente na agenda de discussões e ganhando corpo na estrutura do bloco. Soares (2011) atribui esta mudança a dois fatores: (1) a amplitude econômica que vem alcançando as indústrias criativas no Brasil, na Argentina e no Uruguai, gerando emprego e renda, ampliando a oferta de bens e serviços culturais, impactando positivamente o PIB de cada um destes países; (2) a presença de atores não governamentais no incremento de ações culturais no âmbito do MERCOSUL: professores e pesquisadores universitários, artistas, intelectuais, empresários e Organizações Não Governamentais (ONG). Através de suas ações, estes contribuem para a promoção e difusão da cultura como um todo, possibilitando o compartilhamento de ideias e a criação conjunta de projetos culturais, estreitando as relações entre os países. 
$\mathrm{Na}$ seção seguinte, retoma-se a questão do Protocolo de Integração Cultural, dada a importância deste documento no contexto das ações do MERCOSUL Cultural.

\subsection{O Protocolo de Integração Cultural}

O Protocolo de Integração Cultural do MERCOSUL foi aprovado em reunião do CMC, em 1996, na cidade de Fortaleza (CE). O documento foi elaborado com vistas a balizar as ações do MERCOSUL Cultural. Com as assinaturas dos países membros, registra-se o compromisso mútuo de

[...] promover a cooperação e o intercâmbio entre suas respectivas instituições e agentes culturais, com o objetivo de favorecer o enriquecimento e a difusão das expressões culturais e artísticas do MERCOSUL (MERCOSUL. Conselho de Mercado Comum, 1996, tradução nossa).

Destaca-se, aqui, a recomendação proposta pelo Artigo VI:

Os Estados Partes incentivarão a cooperação entre seus respectivos arquivos históricos, bibliotecas, museus e instituições responsáveis pela preservação do patrimônio cultural, a fim de harmonizar os critérios relativos à classificação, catalogação e preservação, com o objetivo de criar um registro do patrimônio histórico e cultural dos Estados Partes do MERCOSUL (MERCOSUL. Conselho de Mercado Comum, 1996, tradução nossa).

Interessa-nos, especialmente, este artigo, uma vez que demonstra atenção, por parte do bloco, em desenvolver medidas que unam esforços entre os países membros no sentido de assegurar o tratamento técnico e a preservação do seu patrimônio documental. As instituições responsáveis pela preservação do patrimônio cultural citadas no Artigo VI, incluindo-se aqui as bibliotecas, recebem, porém, ênfase apenas nas suas funções técnico-operacionais catalogação, classificação e preservação - deixando-se de lado as questões conceituais e teóricas pertinentes ao tema do patrimônio documental.

O Protocolo recebe críticas, ainda, em relação à visão de cultura e de patrimônio que apresenta, considerada essencialista e conservadora. Martín (2011) salienta a presença de duas visões de cultura no mesmo documento: 
enquanto uma está pautada na diversidade e nos valores comuns, na busca pela cooperação e intercâmbio de culturas e tradições históricas, o que evidencia o seu sentido amplo e antropológico; a outra

[...] circunscreve a ação cultural aos produtores privilegiados, perdendo-se de vista a perspectiva processual e dinâmica, e os Estados retêm para suas agências os resorts relativos à gestão da identidade e dos passados nacionais (MARTìN, 2011, p. 24, grifo do autor).

Para Martín, "A cultura foi enunciada em seu sentido restrito, criada e reproduzida por especialistas, intelectuais e profissionais da cultura." (MARTÍN, 2011, p. 24).

Viva (2011) acrescenta, ainda, que o patrimônio cultural foi abordado no Protocolo sob uma visão conservadora, que privilegia os bens simbólicos do passado. Para a autora, essa visão conservadora provoca uma hierarquização da cultura, em que, por exemplo, a arte vale mais que o artesanato, a cultura escrita mais que a oral, e assim por diante.

\section{O patrimônio documental bibliográfico no âmbito do MERCOSUL}

\section{Cultural}

Através da leitura das atas das Reuniões de Ministros e das Comissões, percebese a preocupação, no MERCOSUL Cultural, com as mais diversas questões relacionadas ao patrimônio cultural, daí a justificativa de sua existência enquanto instância administrativa dentro da organização MERCOSUL. Como neste artigo nosso foco está centrado, especificamente, no tema do patrimônio documental bibliográfico, cabem observações sobre como vem sendo tratado este assunto dentro do espaço do MERCOSUL Cultural.

Ainda na primeira reunião, realizada no ano de 1992, quando começaram as discussões em torno da relevância da Cultura no contexto do bloco econômico, observa-se que o tema do patrimônio bibliográfico se faz presente, através da proposta de realização de atividades conjuntas com as bibliotecas nacionais, conforme especificado no item 9 da ata do evento: 


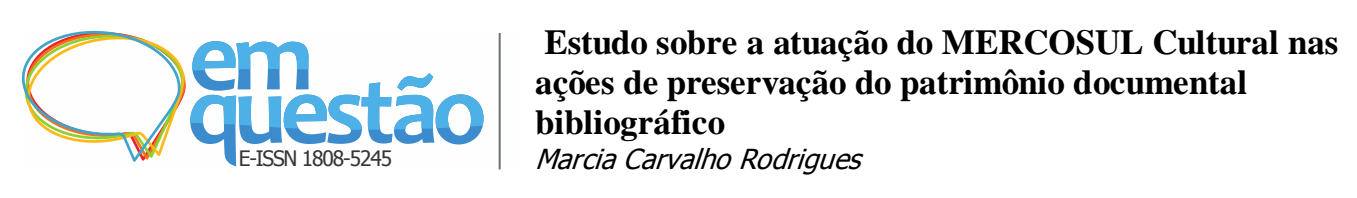

[...] 9. Incentivo à interconexão informatizada das Bibliotecas Nacionais. Reforço dos instrumentos de cooperação interinstitucionais dos Arquivos e Bibliotecas Nacionais (MERCOSUL, 1992, p. 2, tradução nossa).

Da mesma forma, na primeira Reunião Especializada sobre Cultura, no ano de 1995, novamente, são citadas as bibliotecas nacionais e centros de documentação, propondo-se a compatibilização de seus bancos de dados e atividades culturais (MERCOSUL. Reunião Especializada de Cultura, 1995b). Nas duas ocasiões em que as bibliotecas nacionais foram citadas, até 1995, foi proposta a criação de um sistema de integração entre seus catálogos.

Há, também, o já mencionado Artigo VI do Protocolo de Integração Cultural, o qual recomenda a cooperação, no sentido técnico, das instituições culturais presentes nos países membros do MERCOSUL, incluindo-se aí as bibliotecas.

Além das recomendações apresentadas, o que se observa ao longo da história das Reuniões de Ministros e das Comissões, são poucas e breves recomendações e/ou sugestões mencionadas ao longo dos eventos, o que denota uma tímida lembrança das bibliotecas nacionais e do patrimônio bibliográfico como um todo pelos participantes. Em geral, estas recomendações estão voltadas à promoção da leitura; à implementação do projeto Biblioteca do MERCOSUL - posteriormente denominada Biblioteca Especializada e Centro de Documentação sobre MERCOSUL ${ }^{3}$; à criação da Comissão Técnica Biblioteca do MERCOSUL (vinculada ao CCR); e ao incentivo à cooperação técnica entre instituições culturais como bibliotecas, arquivos históricos e museus.

Em 2002, um passo importante foi dado no sentido de impulsionar a valorização do patrimônio bibliográfico dos Estados Parte, com a recomendação, pelo PARCUM, que as bibliotecas nacionais aderissem à Associação de Estados Ibero-americanos para o Desenvolvimento das Bibliotecas Nacionais da Ibero-América (ABINIA) ${ }^{4}$, a fim de conformar um âmbito comum que passaria a ser denominado ABINIA MERCOSUL. Segundo a Disposição, 
A realização desse trâmite é imprescindível para reafirmar a adesão destes países a este organismo internacional. Além disso, a problemática comum das Bibliotecas Nacionais do MERCOSUL exige a integração através de políticas culturais que valorizem a identidade dos respectivos Estados, a fim de construir um quadro cultural comum, para o qual é necessário estabelecer ações compatibilizadoras e a continuação de uma série de medidas [...] (MERCOSUL. Comissão Parlamentar Conjunta, 2002, tradução nossa).

O tema do patrimônio bibliográfico foi tratado de forma pontual e crítica em ocasião de dois eventos que ocorreram paralelamente à agenda do MERCOSUL Cultural, na sequência da recomendação:

a) I Encuentro de Bibliotecas Nacionales del Mercosur y Asociados: deste encontro, participaram representantes das bibliotecas nacionais da Bolívia, do Paraguai, do Uruguay, do Chile, do Brasil e da Argentina. O evento ocorreu entre os dias 3 e 5 de novembro de 2003, na Biblioteca Nacional argentina. Os temas tratados no encontro foram: o planejamento de políticas de informação regionais; a construção de espaços virtuais de consulta comuns; a normalização de padrões para o intercâmbio de informação; a legislação sobre depósito legal; a cooperação em projetos de capacitação de recursos humanos; a difusão de publicações e aquisições (BOLETín ELECTRÓNICO, 2003). Como se vê, o depósito legal de publicações foi um dos temas debatidos, o que diz respeito, diretamente, à preservação do patrimônio bibliográfico de cada uma das nações envolvidas;

b) II Encuentro de Bibliotecas Nacionales del Mercosur y Asociados: ocorrido entre os dias 5 e 7 de dezembro de 2006, em Buenos Aires. Nesta segunda edição do evento, representantes das bibliotecas nacionais do Paraguai, Uruguai, Venezuela, Chile, Bolívia, Argentina, Brasil e Cuba, todas afiliadas à ABINIA, debateram os seguintes temas: intercâmbio bibliográfico e cooperação: diagnóstico da situação atual de cada biblioteca; exposições sobre as coleções de cada uma das bibliotecas nacionais participantes; depósito legal; o conceito de biblioteca nacional; proposta de implementação de centros de informação e documentação do MERCOSUL (ENCUENTRO DE 


\section{BIBLIOTECAS NACIONALES DEL MERCOSUR Y ASOCIADOS,} 2006).

Um dos objetivos centrais do encontro foi o de definir as Bibliotecas Nacionais como pontes culturais entre os países ao promover o intercâmbio de conhecimentos, o diálogo e a cooperação solidária (CARTA MENSUAL, 2006, tradução nossa).

Como resultado do evento, foi produzida a Declaração de Buenos Aires. O documento apresenta uma série de propostas de ações a serem desenvolvidas e implementadas, tais como:

a) a constituição de um núcleo de Bibliotecas Nacionales del MERCOSUR y Asociados, o qual deveria realizar reuniões periódicas e estabelecer oportunidades de colaboração a longo prazo;

b) a adoção de um logotipo comum para as bibliotecas nacionais participantes do bloco;

c) a criação de um portal latino-americano, baseado em formatos digitais que permitam o intercâmbio de informações, elaborado segundo padrões internacionais;

d) o compromisso de realizar um terceiro encontro, em 2007, em Havana, Cuba (CARTA MENSUAL, 2006).

Parte dos trabalhos apresentados no evento foram publicados no fascículo 6 de 2007 do periódico argentino La Biblioteca. Sobre as propostas elencadas na Declaração de Buenos Aires, até o momento, destacam-se:

a) a parceria entre as bibliotecas nacionais do Brasil e da Argentina em um projeto conjunto intitulado Biblioteca Virtual Pedro de Angelis, através do qual estas instituições compartilham esforços, conhecimentos e tecnologias para disponibilizar as obras escritas, editadas e/ou pertencentes ao bibliógrafo italiano Pedro de Angelis. A coleção, adquirida em 1853 por D. Pedro II, integra o acervo da Biblioteca Nacional brasileira, e se compõe de 1.533 exemplares, dos quais: 88 são obras impressas, 1.300 são manuscritos, 52 são litografias e 93 são mapas (BETTENCOURT; BARBER, 2009). 


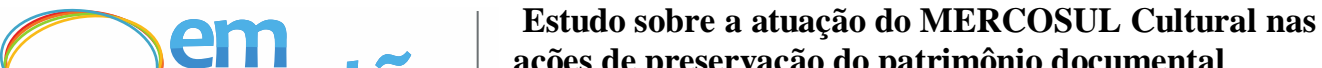 ações de preservação do patrimônio documental bibliográfico \\ Marcia Carvalho Rodrigues}

Foi na Argentina que Pedro de Angelis formou sua coleção de livros e documentos, organizada e relacionada no catálogo da coleção intitulado Impresos y Manuscritos de Obras que Tratan Principalmente del Río de la Plata, que mais tarde vendeu ao Brasil nas negociações mediadas por José María da Silva Paranhos, Visconde de Rio Branco (BETTENCOURT; BARBER, 2009, p. 6, tradução nossa).

Através do convênio assinado em maio de 2008, firmou-se o seguinte compromisso:

[...] a Biblioteca Nacional do Brasil assume a responsabilidade de:

- disponibilizar a base de dados para o acesso ao carregamento remoto pela Biblioteca Nacional Argentina,

- receber e incluir os textos, os registros da base de dados e os arquivos digitais enviados pela biblioteca argentina no sítio Web do projeto,

- processar a informação recebida e gerar os arquivos derivados para sua publicação no sítio Web da Biblioteca Digital.

Por sua vez, a Biblioteca Nacional Argentina se compromete a:

- selecionar o fundo bibliográfico a ser incluído na Biblioteca

Digital,

- selecionar os arquivos a serem incluídos no sítio entre aqueles documentos já digitalizados,

- analisar os conteúdos digitais selecionados,

- elaborar os textos de apresentação e contextualização dos documentos a serem incluídos na Biblioteca Digital,

- enviar os textos, os registros da base de dados e os arquivos digitais à Biblioteca Nacional do Brasil, de acordo com os padrões definidos para a Biblioteca Digital,

- revisar os conteúdos elaborados para sua inclusão no sítio (BETTENCOURT; BARBER, 2009, p. 5, tradução nossa).

O projeto Biblioteca Virtual Pedro de Angelis encontra-se disponível em: http://bndigital.bn.br/projetos/angelis/ (FUNDAÇÃO BIBLIOTECA NACIONAL, 2009);

b) a digitalização de documentos sobre a Guerra do Paraguai (1864-1870) o acervo é composto por livros, jornais, gravuras, desenhos e mapas, e pode ser consultado no site da Biblioteca Digital do Patrimônio Iberoamericano - (BDPI), promovido pela ABINIA, em http://www.iberoamericadigital.net/pt/ (ASSOCIAÇÃO DE ESTADOS IBERO-AMERICANOS..., [2013]). A coleção digital, denominada Acervos da Guerra Grande, é parte do Programa Regional Além da Guerra: memória, reflexão e cultura da paz, promovido pelo MERCOSUL Cultural. 
Os Encuentros de Bibliotecas Nacionales del MERCOSUR y Asociados, por sua vez, findaram em 2006.

\section{Considerações finais}

A hipótese levantada neste estudo, a qual se confirmou após a realização da pesquisa, se baseou na suposição de que, apesar de algumas iniciativas terem sido tomadas no sentido de buscar alternativas conjuntas para preservar e valorizar o patrimônio cultural dos países que integram o MERCOSUL, a cultura, de uma maneira geral, não tem ocupado posição de destaque nas ações e iniciativas do bloco.

Houve a criação do MERCOSUL Cultural, órgão responsável por buscar o fortalecimento do bloco, tratando a cultura como elemento fundamental para a integração regional, porém, de uma maneira geral, o que se observa é que a cultura só começa a ser utilizada, timidamente, como instrumento de aproximação das sociedades ou como facilitadora do avanço rumo à integração regional, a partir da segunda metade da década de 2000 - em grande parte devido ao crescimento das indústrias criativas no Brasil, na Argentina e no Uruguai.

Desde a sua instituição, a missão do MERCOSUL Cultural tem sido buscar compatibilizar legislações, intercambiar informações, capacitar mão-deobra e incentivar o turismo cultural, além de desenvolver outras atividades conjuntas com organismos internacionais. Entretanto, até o momento, não existe, por exemplo, uma convenção ou recomendação para uso coletivo dos países que integram o acordo, orientando ações de preservação e valorização do patrimônio documental bibliográfico. Em relação a este tema, há somente a recomendação, feita em 2002 aos Estados membros, para que assinassem a ata constitutiva da ABINIA, passando a integrar esta entidade. A ABINIA, por sua vez, no mesmo ano criou cinco sub-regiões, sendo uma destas denominada MERCOSUL, à qual se incorporou o Chile. A criação destas sub-regiões visou a facilitar a realização de projetos e ações alinhados às necessidades ou interesses comuns às bibliotecas nacionais integrantes (ASSOCIAÇÃO DE ESTADOS 
IBERO-AMERICANOS..., [2003]). Em termos práticos, poucas ações têm sido desenvolvidas.

Nestor García Canclini, um dos maiores estudiosos contemporâneos das problemáticas culturais latino-americanas, em ocasião de uma visita à Quinta Bienal do MERCOSUL, em 2005, salientou que o verdadeiro sentido de buscar uma integração entre os países da América Latina consiste na razão da multiplicidade de identidades presente nos países, sendo esse seu principal atrativo (FUNDAÇÃO BIENAL DO MERCOSUL, 2012). A união através do MERCOSUL propiciaria maior possibilidade de competência internacional, além de estimular a cooperação no âmbito da produção e da circulação de bens culturais. Soares (2011), da mesma forma, salienta a importância da cultura nas relações internacionais, enfatizando a relevância da diplomacia cultural, termo cunhado por Willy Brand (ex-ministro alemão), para os quais a cultura seria a terceira base do tripé que sustenta a política externa dos países, juntamente com as bases política e comercial.

Neste sentido, um exemplo bastante interessante, cofinanciado pela União Europeia, é o projeto Europeana. Tal projeto, de grandes dimensões, busca desenvolver uma base virtual do patrimônio bibliográfico de todas as nações pertencentes ao bloco econômico. Para tanto, efetiva-se através de uma rede de cooperação entre as bibliotecas nacionais e outras instituições culturais pertencentes aos Estados membros, e tem como missão tornar acessível o patrimônio cultural da Europa. Iniciativa semelhante desenvolve a ABINIA, através do projeto Biblioteca Digital do Patrimônio Ibero-americano, ao qual foi incorporado, recentemente, o projeto Além da Guerra: memória, reflexão e cultura da paz.

Assim, para que os países do MERCOSUL desenvolvam ações conjuntas de preservação e salvaguarda do patrimônio documental, é necessário que, primeiramente, conheçam efetivamente o patrimônio que detêm, reconheçam a sua importância e passem a visualizar a cultura como instrumento privilegiado de cooperação econômica. A presença dessa lacuna nas ações do MERCOSUL evidencia a necessidade de estímulo a estudos e pesquisas referentes à busca pela integração entre os países, dando a devida consideração às questões de 
ordem cultural, trazendo à tona a importância dos estudos voltados à preservação e à valorização do patrimônio cultural das nações.

\section{Referências}

ALADI. O que significou a substituição da ALALC pela ALADI?

Montevideo, c2016. Disponível em: 〈http://goo.gl/v0XsR>. Acesso em: 23 ago. 2016.

AMICCI, Daniel. Construccion de la identidad em el regionalismo americano: interrogantes del MERCOSUR. Iberoamérica, Moscou, n. 4, p. 104-124, 2012. Disponível em: 〈https://goo.gl/woSfbJ>. Acesso em: 14 set. 2016.

ASSOCIAÇÃO DE ESTADOS IBERO-AMERICANOS para o Desenvolvimento das Bibliotecas Nacionais da Ibero-América. Acerca de ABINIA: objetivos. Caracas, 2017. Disponível em: 〈https://goo.gl/smNij〉. Acesso em: 28 abr. 2017.

ASSOCIAÇÃO DE ESTADOS IBERO-AMERICANOS para o Desenvolvimento das Bibliotecas Nacionais da Ibero-América. Biblioteca Digital del Patrimonio Iberoamericano. [Madrid, 2013]. Disponível em: <https://goo.gl/x4FRJd>. Acesso em: 27 jul. 2017.

ASSOCIAÇÃO DE ESTADOS IBERO-AMERICANOS para o Desenvolvimento das Bibliotecas Nacionais da Ibero-América. Asambléa general, 14., 2003, Ciudad de México. Resolución sobre creación de subregiones. [Ciudad de Mexico, 2003]. Disponível em: 〈https://goo.g1/Y6fWvE〉. Acesso em: 16 set. 2016.

BETTENCOURT, Angela Monteiro; BARBER, Elsa. Biblioteca Virtual Pedro de Angelis: interoperabilidad en el acceso y preservación del patrimonio cultural en América Latina. In: WORLD LIBRARY AND INFORMATION CONGRESS, 75., 2009, Milão; IFLA GENERAL CONFERENCE AND COUNCIL, 75., 2009, Milão. Programme and proceedings. [Haia]: IFLA, 2009. Disponível em: 〈https://goo.gl/KW0UwS〉. Acesso em: 21 set. 2016.

BOLETÍN ELECTRÓNICO, Buenos Aires, v. 1, n. 3, Dic. 2003. Disponível em: 〈https://goo.gl/qYS9gY>. Acesso em: 14 set. 2016.

BRASIL. Congresso. Comissão Parlamentar Conjunta do MERCOSUL. Globalização e integração. [Brasília, 200?]. Disponível em: <https://goo.gl/PhoJcW>. Acesso em: 4 ago. 2016.

BRASIL. Ministério do Desenvolvimento, Indústria e Comércio Exterior. Acordo de complementação econômica no 14: Brasil/Argentina. Brasília, [2015]. Disponível em: 〈https://goo.gl/1AQLBX>. Acesso em: 04 ago. 2016. 
CARTA MENSUAL, Buenos Aires, n. 125, Dic. 2006. Disponível em: <https://goo.g1/ugcug2>. Acesso em: 16 set. 2016.

CARVALHO, Leonardo Arquimino de. Os processos de integração econômica regional da União Européia e do Mercosul: breve abordagem históricoevolutiva. Scientia-Iuris, Londrina, v. 5-6, 2001-2002. Disponível em: <https://goo.gl/wyo5AR>. Acesso em: 4 ago. 2016.

ENCUENTRO DE BIBLIOTECAS NACIONALES DEL MERCOSUR Y ASOCIADOS, 2., 2006, Buenos Aires. Cronograma de actividades. Buenos Aires: BID, 2006. Disponível em: 〈https://goo.gl/0TBNPI>. Acesso em: 16 set. 2016.

FUNDAÇÃO BIBLIOTECA NACIONAL. Projeto: Biblioteca Virtual Pedro de Angelis. Rio de Janeiro, 2009. Disponível em: 〈https://goo.g1/7ZqAFX〉. Acesso em: 27 jul. 2017.

FUNDAÇÃO BIENAL DO MERCOSUL. Nestor Canclini traça um panorama da Bienal do MERCOSUL. [Porto Alegre, 2012]. Disponível em: <http://goo.gl/0h9zNU>. Acesso em: 19 nov. 2012.

HARVEY, Edwin R. El Tratado de Asunción y el MERCOSUR Cultural: relación con otros procesos de integración regional. In:

MERCOSUL/MERCOSUR: the market \& beyond, 2001, Austin.

[Proceedings...]. Austin: University of Texas, 2001. Disponível em: <http://goo.g1/3vNsF9>. Acesso em: 23 ago. 2016.

INSTITUTO DO PATRIMÔNIO HISTÓRICO E ARTÍSTICO NACIONAL. Comissão de Patrimônio Cultural do MERCOSUL (CPC). Brasília, c2014. Disponível em: <https://goo.gl/MVHUqQ>. Acesso em: 14 set. 2016.

LEME, Álvaro Augusto Stumpf Paes. A Declaração de Iguaçu (1985): a nova cooperação argentino-brasileira. 2006. Dissertação (Mestrado) - Programa de Pós-Graduação em Relações Internacionais, Universidade Federal do Rio Grande do Sul, Porto Alegre, 2006. Disponível em: 〈https://goo.g1/fyeGAW〉. Acesso: 4 ago. 2016.

MARTIN, Alicia. Gestão e agências da cultura e o patrimônio no MERCOSUL. In: FERREIRA, Lúcio Menezes; FERREIRA, Maria Letícia Mazzucchi; ROTMAN, Mónica B. (Org.). Patrimônio cultural no Brasil e na Argentina: estudos de caso. São Paulo: Annablume, 2011. p. 19-32.

MERCOSUL. Acta de la Reunion de los secretarios de cultura y autoridades culturales del MERCOSUR. Brasília, 25 ago. 1992. Disponível em:

<https://goo.gl/q5Lx8f>. Acesso em: 2 set. 2016. 
MERCOSUL Em poucas palavras. Montevideo, 2016a. Disponível em: <http://goo.gl/HLJhvu>. Acesso em: 20 ago. 2016

MERCOSUL. Estrutura institucional do MERCOSUL. Buenos Aires, 2012. Disponível em: <https://goo.g1/5Gmc6G>. Acesso em: 14 set. 2016.

MERCOSUL. MERCOSUL Cultural. Buenos Aires, 2016b. Disponível em: <http://goo.gl/q3TNnZ>. Acesso em: 25 ago. 2016.

MERCOSUL Saiba mais sobre o MERCOSUL. Montevideo, 2015. Disponível em: <http://goo.g1/XH52pj〉. Acesso em: 24 ago. 2015.

MERCOSUL. Biblioteca especializada y Centro de Documentación sobre MERCOSUR (Mercado Común del Sur). Reglamento de préstamo. Buenos Aires, 2009. Disponível em: 〈https://goo.gl/b0JkgK〉. Acesso em: 14 set. 2016.

MERCOSUL. Comissão Parlamentar Conjunta. MERCOSUR/CPC/DIS. 17/2002: bibliotecas nacionales em latinoamerica. Brasília, 2002. Disponível em: 〈https://goo.gl/575PFV〉. Acesso em: 16 set. 2016.

MERCOSUL. Conselho de Mercado Comum. MERCOSUR/CMC/DEC. $\mathbf{N}^{\mathbf{0}}$ 2/95: Reunión de Ministros de Cultura. Assunción, 1995. Disponível em: <http://goo.g1/q6hAU8>. Acesso em: 23 ago. 2016.

MERCOSUL. Conselho de Mercado Comum. MERCOSUR/CMC/DEC N $\mathbf{N}^{\circ}$ 11/96: Protocolo de Integracion Cultural del MERCOSUR. Fortaleza, 1996. Disponível em: <http://goo.gl/d0YnDJ>. Acesso em: 23 ago. 2016.

MERCOSUL. Conselho de Mercado Comum. MERCOSUR/CMC/DEC $\mathbf{N}^{\circ}$ 33/08: Selo Mercosul Cultural. Salvador, 2008. Disponível em: <https://goo.gl/h6BnDK>. Acesso em: 23 ago. 2016.

MERCOSUL. Conselho de Mercado Comum. MERCOSUR/CMC/DEC. $\mathbf{N}^{\mathbf{o}}$ 38/10: Fondo MERCOSUR Cultural. Foz de Iguazú, 2010. Disponível em: <http://goo.g1/NN2KA9>. Acesso em: 23 ago. 2016.

MERCOSUL. Conselho de Mercado Comum. MERCOSUL/CMC/DEC. $\mathbf{N}^{\mathbf{0}}$ 55/12: Patrimônio Cultural do MERCOSUL. Brasília, 2012. Disponível em: <https://goo.g1/Dc0Q4k>. Acesso em: 24 ago. 2016.

MERCOSUL. Conselho de Mercado Comum. MERCOSUL/CMC/DEC. $\mathbf{N}^{\mathbf{0}}$ 22/14: estrutura orgânica e regulamento interno do MERCOSUL Cultural. [S.1.], 2014. Disponível em: 〈https://goo.gl/QAc24f>. Acesso em: 24 ago. 2016

MERCOSUL. Grupo Mercado Comum. MERCOSUL/GMC/RES N. 34/92: criação da Reunião Especializada sobre Cultura. [Brasília], 1992. Disponível em: 〈http://goo.gl/KkPy8v>. Acesso em: 23 ago. 2016. 
MERCOSUL. Reunião Especializada de Cultura, 1., 1995, Buenos Aires. Acta 01/95. Buenos Aires, 1995a. Disponível em: <https://goo.gl/shxDHu>. Acesso em: 2 set. 2016.

MERCOSUL. Reunião Especializada de Cultura, 2, 1995, Assunção. Acta 02/95: acta de Asuncion. Asunción, 1995b. Disponível em: <https://goo.gl/shxDHu>. Acesso em: 2 set. 2016.

SOARES, Maria Susana Arrosa. Balance y perspectivas del MERCOSUR Cultural: 20 años de existencia. In: BRICEÑO RUIZ, José (Ed.). El Mercosur y las complejidades de la integración regional. Buenos Aires: Teseo, 2011. Disponível em: <https://goo.gl/qMFKlZ>. Acesso em: 14 set. 2016.

VIVA, Julieta. MERCOSUR Cultural. Pampa: Revista Interuniversitaria de Estudios Territoriales, Santa Fé, n. 7, p. 159-169, 2011. Disponível em: <http://goo.gl/6bq0Ov>. Acesso em: 23 ago. 2016.

\title{
Study on the performance of MERCOSUR Cultural in the actions of preservation of bibliographic documentary heritage
}

\begin{abstract}
This article has a brief history of MERCOSUR and MERCOSUR Cultural, the responsible entity for promoting and disseminating the cultural values and traditions of the countries of the bloc. The study proposed to investigate the actions of MERCOSUR Cultural with a view to the preservation of bibliographic documentary heritage. Following a qualitative approach, it made use of bibliographical and documentary revisions for theoretical construction. The results of the research demonstrate that culture, in general, has not occupied a prominent position in the actions and initiatives of MERCOSUR. The presence of this gap shows the need to stimulate studies and research concerning the search for integration among countries, giving due consideration to cultural issues, bringing to the fore the importance of studies aimed at preserving and valuing the cultural heritage of nations.
\end{abstract}

Keywords: Bibliographic documentary heritage. Cultural heritage. MERCOSUR.

Recebido: 18/03/2017

Aceito: $13 / 05 / 2017$ 
1 BANDEIRA, Moniz. Estado nacional e política internacional na América Latina: o continente nas relações Argentina-Brasil (1930-1992). 2. ed. São Paulo: Ensaio, 1995. Apud Carvalho (2001-2002).

2 A ALADI foi criada em 1980, através do Tratado de Montevidéu, substituindo e dando continuidade ao acordo firmado através do Tratado de 1960 que criou a Associação LatinoAmericana de Livre-Comércio (ALALC). "Ambos os Tratados coincidiam nos seus objetivos e tinham como meta final o estabelecimento, a longo prazo, de um mercado comum latinoamericano." (ALADI, 2016).

3 A Biblioteca do MERCOSUL está localizada no Edifício Sede do MERCOSUL, em Montevidéu, Uruguai. Os seguintes usuários podem fazer uso da Biblioteca e de suas instalações: funcionários da Secretaria do MERCOSUL, funcionários das representações permanentes e delegados dos Estados parte do MERCOSUL e Associados, pessoal contratado pela Secretaria ou vinculado a instituições com as quais se mantém acordo de cooperação (universidades, consultores), público externo (MERCOSUL. Biblioteca especializada y Centro de Documentación sobre MERCOSUR, 2009).

4 “A Associação de Bibliotecas Nacionais da Ibero América (ABINIA), fundada no México a 14 de dezembro de 1989, é um fórum inter regional que reúne as 22 Bibliotecas Nacionais da Ibero América. Em outubro de 1999 se aprovou em Lima, Peru a ata constitutiva que lhe outorga o caráter de Organismo internacional, com uma nova denominação: Associação de Estados Ibero americanos para o Desenvolvimento das Bibliotecas Nacionais de Ibero América, mantendo-se a denominação de ABINIA. Até junho de 2002, a ata constitutiva foi ratificada por 10 países da Ibero América." (ASSOCIAÇÃO DE ESTADOS IBEROAMERICANOS..., 2017, tradução nossa). Atualmente, os seguintes países integram a ABINIA: Costa Rica, Guatemala, Cuba, Equador, El Salvador, Espanha, Portugal, Chile, México, Porto Rico, Argentina, Uruguai, Nicarágua, Panamá, Paraguai, Honduras, Peru, Colômbia, Bolívia, Venezuela, República Dominicana e Brasil. 